\title{
Body size and subcutaneous fat patterning in adolescence
}

\author{
Jean W A Matthes, P A Lewis, D P Davies, Jaqueline A Bethel
}

\begin{abstract}
Factors that influence low birth weight at term may also be associated with subcutaneous fat patterning in later life. This hypothesis was investigated in a comparative (retrospective) cohort study. The subjects, born in Cardiff between 1975 and 1977, were of mean age 15.7 years. Cases (low birth weight $(<2500 \mathrm{~g})$ at term) were matched with controls (normal birth weight (3000-3800 g) at term) for sex, parity, place of birth, date of birth, and gestation. Subscapular skinfold (an index of central subcutaneous fat) and triceps skinfold (an index of peripheral subcutaneous fat) were measured using a Holtain skinfold caliper. The differences (cases minus controls) (95\% confidence interval) for subscapular and triceps skinfolds were respectively $-0.3 \mathrm{~mm}(-1.74$ to 1.14$)$ and $-0.48 \mathrm{~mm}$ ( -1.75 to 0.79$)$. These findings are inconsistent with the hypothesis that low birth weight at term is associated with subcutaneous fat patterning in adolescence.

(Arch Dis Child 1996;75:521-523)
\end{abstract}

Keywords: birth weight, adolescence, body size, fat patterning.

The hypothesis that low birth weight and poor weight gain in infancy are linked with adult cardiovascular disease includes the association of low birth weight with later truncal fat deposition. ${ }^{12}$ Truncal obesity is a risk factor for adult death from coronary artery disease (CHD), and is also associated with high blood pressure, high triglyceride levels, low levels of high density lipoprotein, and an increased incidence of non-insulin dependent diabetes mellitus. ${ }^{3}$ Studies that initially drew attention to the relationship between birth weight and fat deposition were based on historical cohorts born in Hertfordshire and Preston in the 1920s and $1930 \mathrm{~s},{ }^{2}$ at a time when infant mortality was high, thus introducing the potential for an ascertainment (survivor) bias. Our study examines the hypothesis that low birth weight at term (a proxy for fetal growth retardation) is linked with subcutaneous fat patterning on a cohort born between 1975 and 1977. Two groups of adolescents were studied, one of low birth weight at term and the other of normal birth weight.

\section{Patients and methods}

This is a secondary analysis of a retrospective (comparative) cohort study to investigate the associations between birth weight and later blood pressure and lung function. ${ }^{4}$ The subjects were identified from the Cardiff Birth Survey (CBS), which has documented every birth in Cardiff and later in South Glamorgan since 1965. Details of the study protocol including calculation of sample size, identification and matching of cases and controls, and tracing of subjects have been described in detail previously. ${ }^{4}$ To highlight the salient features, the cases were born at 38 to 42 weeks' gestation and weighed less than $2500 \mathrm{~g}$. As a group they were considered to have suffered intrauterine growth retardation. The controls weighed $\mathbf{3 0 0 0}$ to $3800 \mathrm{~g}$ and were considered to have been adequately nourished in utero. Infants born from multiple pregnancies were excluded, as were those recorded in the CBS as not surviving or having a congenital abnormality or severe medical condition. For each case a list of eligible controls was drawn up with the aid of a computer. Cases and controls were matched for sex, parity, gestation, date of birth, and hospital of delivery. Prior rules for the selection of the controls were applied in sequence until a match was found.

The subjects were traced and visited at home by one of two trained observers unaware of case control status. Data were collected on the occupation of the chief wage earner in the household and this was later used to assign social class. Weight was measured to the nearest $100 \mathrm{~g}$ with the subject lightly clothed and without shoes using a portable Soenle scale. Height was measured with a portable Harpenden stadiometer. Occipitofrontal head circumference and mid arm circumference were each measured in triplicate to the nearest millimetre using a Harpenden tape measure. Skinfold measurements were taken in triplicate on the subject's left side to the nearest $0.2 \mathrm{~mm}$ using a Holtain skinfold caliper by the method of Cameron. ${ }^{5}$ Triceps skinfold was measured halfway between the acromion process and olecranon process, and the subscapular skinfold just below the tip of the scapula. The definitive measurements were the means of the last two readings.

The data were analysed using the SPSS-PC package. ${ }^{6}$ The differences between the two groups were compared using a paired $t$ test.

\section{Results}

The academic year cohorts from 1 September 1975 to 31 August 1977 yielded 230 eligible cases. Of these, six had died and two were excluded because of medical conditions (pseudohypoparathyroidism and severe cer- 
Table 1 Anthropometric measurements of cases and controls

\begin{tabular}{|c|c|c|c|c|c|}
\hline & Mean & $S D$ & Median & Min & $\operatorname{Max}$ \\
\hline \multicolumn{6}{|l|}{ Weight (kg) } \\
\hline Cases & 52.1 & 9.0 & 51.4 & 33.4 & 80.0 \\
\hline Controls & 58.4 & 11.7 & 57.1 & 33.0 & 110.6 \\
\hline Difference & -6.3 & 14.7 & -5.5 & 28.8 & -71.8 \\
\hline & \multicolumn{5}{|c|}{$95 \% \mathrm{CI}-8.6$ to -4.0} \\
\hline \multicolumn{6}{|l|}{ Height (cm) } \\
\hline Cases & 160.7 & 7.72 & 160.9 & 134.0 & 185.0 \\
\hline Controls & 166.1 & 7.96 & 165.1 & 148.0 & 185.1 \\
\hline Difference & -5.4 & 9.6 & -5.0 & 20.2 & -33.3 \\
\hline & \multicolumn{5}{|c|}{$95 \% \mathrm{CI}-6.9$ to -3.9} \\
\hline \multicolumn{6}{|c|}{ Body mass index $\left(\mathrm{kg} / \mathrm{m}^{2}\right)$} \\
\hline Cases & 20.2 & 3.1 & 19.9 & 12.9 & 29.0 \\
\hline Controls & 21.1 & 3.7 & 20.7 & 13.4 & 35.8 \\
\hline Difference & -0.9 & 4.9 & -0.4 & 10.6 & -18.1 \\
\hline & \multicolumn{5}{|c|}{$95 \% \mathrm{CI}-1.7$ to -0.2} \\
\hline \multicolumn{6}{|c|}{ Mid arm circumference (mm) } \\
\hline Cases & 236.4 & 23.9 & 232 & 183 & 318.0 \\
\hline Controls & 246.6 & 26.0 & 245 & 190 & 348.0 \\
\hline Difference & -10.2 & 33.9 & -9 & -114 & 81.0 \\
\hline & \multicolumn{5}{|c|}{$95 \% \mathrm{CI}-15.37$ to -5.03} \\
\hline \multicolumn{6}{|c|}{ Head circumference (mm) } \\
\hline Cases & 543.4 & 15.6 & 543 & 507.0 & 583.0 \\
\hline Controls & 558.0 & 17.1 & 556 & 522.0 & 605.0 \\
\hline \multirow[t]{2}{*}{ Difference } & -14.6 & 21.2 & -14 & -59.0 & 54.0 \\
\hline & \multicolumn{5}{|c|}{$95 \%$ CI -17.0 to -12.22} \\
\hline \multicolumn{6}{|c|}{ Triceps skinfold (mm) } \\
\hline Cases & 16.3 & 6.9 & 15.0 & 4.4 & 34.2 \\
\hline Controls & 16.8 & 7.2 & 16.8 & 5.0 & 37.8 \\
\hline Difference & -0.5 & 8.26 & 0.04 & -27.2 & 20.6 \\
\hline & $95 \% \mathrm{CI}$ & -1.75 to 0.79 & & & \\
\hline \multicolumn{6}{|c|}{ Subscapular skinfold (mm) } \\
\hline Cases & 14.6 & 7.0 & 13.1 & 5.0 & 38.2 \\
\hline Controls & 14.9 & 7.7 & 12.6 & 5.4 & 40.0 \\
\hline \multirow[t]{2}{*}{ Difference } & -0.3 & 9.3 & 0.1 & -32.8 & 28.0 \\
\hline & \multicolumn{5}{|c|}{$95 \% \mathrm{CI}-1.74$ to 1.14} \\
\hline \multicolumn{6}{|c|}{ Ratio TSF/SSSF } \\
\hline Cases & 1.2 & 0.5 & 1.1 & 0.4 & 4.3 \\
\hline Controls & 1.2 & 0.4 & 1.1 & 0.5 & 3.0 \\
\hline \multirow{2}{*}{ Difference } & -0.02 & 0.6 & -2.6 & -1.5 & 3.3 \\
\hline & $95 \% \mathrm{CI}$ & -0.11 to 0.07 & & & \\
\hline
\end{tabular}

CI, confidence interval; TSF, triceps skinfolds; SSSF, subscapular skinfold.

ebral palsy) which had not been recorded in the CBS, leaving a cohort of 222 . The records of five were marked as confidential-not to be used for research purposes, four were living abroad, 17 could not be traced, and 19 refused to participate. In the end 177 cases were studied and, for these, 165 controls were seen, representing $74 \%(165 / 222)$ of the case-control pairs. The cases tended to be of lower social class than the controls. Mean birth weight was $2250 \mathrm{~g}$ for cases and $3330 \mathrm{~g}$ for controls. The mean age was 15.6 years for the cases and 15.8 years for the controls. For the cases mean height and weight were $5.4 \mathrm{~cm}$ and $6.3 \mathrm{~kg}$ less than the controls. These differences were statistically significant. The cases also had lower body mass indices and smaller head circumferences and mid arm circumferences.

Table 2 Differences disaggregated by sex

\begin{tabular}{|c|c|c|c|c|c|}
\hline & No (pairs) & Mean & $S D$ & $S E$ & $95 \% C I$ \\
\hline \multicolumn{6}{|l|}{ Weight (kg) } \\
\hline Males & 63 & -10.02 & 16.32 & 2.06 & -14.13 to -5.9 \\
\hline Females & 101 & -4.02 & 13.15 & 1.31 & -6.62 to -1.43 \\
\hline \multicolumn{6}{|l|}{ Height $(\mathrm{cm})$} \\
\hline Males & 63 & -7.8 & 9.92 & 1.25 & -10.3 to -5.34 \\
\hline Females & 102 & -3.8 & 9.04 & 0.9 & -5.6 to -2.07 \\
\hline \multicolumn{6}{|c|}{ Body mass index $\left(\mathrm{kg} / \mathrm{m}^{2}\right)$} \\
\hline Males & 63 & -1.66 & 4.74 & 0.6 & -2.86 to -0.46 \\
\hline Females & 101 & -0.48 & 4.91 & 0.49 & -1.46 to 0.5 \\
\hline \multicolumn{6}{|c|}{ Triceps skinfold (mm) } \\
\hline Males & 63 & -0.3 & 8.8 & 1.1 & -2.6 to 1.9 \\
\hline Females & 102 & -0.6 & 7.9 & 0.8 & -2.1 to 1.0 \\
\hline \multicolumn{6}{|c|}{ Subscapular skinfold (mm) } \\
\hline Males & 63 & -1.0 & 8.9 & 1.1 & -3.2 to 1.3 \\
\hline Females & 102 & 0.1 & 9.6 & 1.0 & -1.8 to 2.0 \\
\hline
\end{tabular}

$\mathrm{CI}$, confidence interval.
However, there were no significant differences in skinfold measurements. These results are shown in table 1 . A repeat of the analysis disaggregated by sex showed a similar pattern (table 2).

\section{Discussion}

A strength of this study is that it is based on the population of a well defined geographical location with 8920 births for the specified study period, with only the cases of particular interest selected for study. Measurements of body length, skinfolds, and head circumference at birth were not recorded in the CBS. However, babies born at term with birth weights less than $2500 \mathrm{~g}$ are recognised in general to be thin and scrawny with a lack of subcutaneous fat and muscle. ${ }^{7}$ Most show 'catch up' growth during the first few months. The adolescents in our study who were of low birth weight at term are therefore likely as a group to have suffered intrauterine growth retardation mainly in the third trimester due to uteroplacental insufficiency. The cases were significantly shorter and lighter than the controls and these differences were more marked for the boys than the girls.

In our study we chose subscapular and triceps skinfold thicknesses as indices of central and peripheral subcutaneous fat respectively. Our findings show no difference in subcutaneous fat patterning between 15 year old individuals of low and normal birth weight at term. They therefore do not support the hypothesis that slow fetal growth programmes specific patterning of adolescent adiposity and, by inference, risk of CHD.

Previous studies have used the waist to hip ratio as an index of truncal obesity. In designing our study, we were concerned that these young adolescents seen at home might have been embarrassed by the measurement of hip size, and been reluctant to participate in the study. Also, at younger ages the ratio of waist to hip size is not as good an indicator of regional fat distribution as the measurement of skinfolds. ${ }^{8}$ It has been suggested that waist hip ratio should be abandoned as an indicator of regional fat distribution, hip circumference not depending on adiposity, in favour of either waist circumference or skinfold measurements. ${ }^{9}$ While waist circumference is a good predictor of ischaemic heart disease in men, it is not such a good predictor in women. ${ }^{10}$ Subscapular skinfold is positively and significantly associated with the risk of ischaemic heart disease ${ }^{10}$ in both sexes. It is also associated with the following independent risk factors: systolic blood pressure, ${ }^{11}$ pre B lipoprotein cholesterol, ${ }^{12}$ fibrinogen and factor VII, ${ }^{13}$ and impaired glucose tolerance, ${ }^{14}$ all independent risk factors for CHD. Subscapular skinfold has greater predictive power than triceps skinfold for raised systolic blood pressure, ${ }^{15}$ adverse blood lipid profile, ${ }^{16}$ and impaired glucose tolerance. ${ }^{14}$

Another study ${ }^{17}$ of a biracial group of Mexican Americans and non-Hispanic white people aged approximately 30 years showed an association between low birth weight and increased truncal fat deposition measured as subscapular 
to triceps ratio. There was also an association between birth weight and current socioeconomic score so that the results might be explained by confounding due to an adverse extrauterine environment. Our study sought to minimise this confounding influence by studying subjects many of whom had not left full time education and whose environments were similar for part of the day.

It is possible that the cases and controls might have been at different pubertal status. ${ }^{18}$ As the mean age of the group was 15.7 years, this seems unlikely for the girls, who would be expected to be approaching the end of their growth spurt, but might be true for boys. However, disaggregating the skinfold data by sex made no appreciable difference to the results.

Our results are inconsistent with the hypothesis that low birth weight at term is associated with fat patterning in adolescence and question the link between intrauterine growth rate and later metabolic abnormalities which are the major risk factors for ischaemic heart disease.

This study was supported by a grant from Children Nationwide. We thank the steering committee of the CBS for the use of th data. Mrs D Savory conducted much of the fieldwork. We are also grateful for the willing cooperation of all of the subjects.

1 Barker DJP, editor. Fetal and infant origins of adult disease. London: BMJ Publications, 1992.

2 Law CM, Barker DJP, Osmond C, Fall CHD, Simmonds SJ Early growth and abdominal fatness in adult life. $\mathcal{f}$ Epidemiol Community Health 1992;46:184-6.

3 Reaven GM. Role of insulin resistance in human disease. Diabetes 1988;37:1595-607.

4 Matthes JWA, Lewis PA, Davies DP, Bethel J. The relationship between birth weight at term and systolic blood pressure in adolescence. $B M \mathcal{Y} 1994 ; 308: 1074-7$.
5 Cameron N. The methods of auxological anthropometry. In: Falkner F, Tanner JM, eds. Human growth, vol 2: postnatal growth. New York: Plenum Press, 1978:35-90.

6 Norusis MJ. SPSS/PC +4 base manual. Chicago: SPSS Inc, 1990.

7 Davies DP, Platts P, Pritchard JM, Wilkinson PW. Nutritional status of light for dates infants at birth and its
influence on early postnatal growth. Arch Dis Child 1979;54:703-6.

8 Deurenberg P, Pieters JJ, Hautvast AJ. The assessment of the body fat percentage by skinfold thickness measurements in childhood and young adolescence. $\mathrm{Br} \mathcal{F}$ Nutr 1990;63:293-303.

9 Despres JP, Moorjani S, Lupien PJ, Tremblay A, Nadeau A, Bouchard C. Regional distribution of body fat, plasma lipoproteins and cardiovascular disease. Arteriosclerosis 1990;10:497-511.

10 Higgins M, Kannel W, Garrison R, Pinsky J, Stokes J. Hazards of obesity - the Framingham experience. Acta Med Scand (Suppl) 1987;723:23-36.

11 Blair D, Habicht JP, Sims EA, Sylwester D, Abraham S. Evidence for an increased risk for hypertension with centrally located body fat and the effect of race and sex on this risk. Am $\mathcal{F}$ Epidemiol 1984;119:526-40.

12 Berenson GS, Webber LS, Srinivasan SR, Voors AW, Harsha DW, Dalferes ER. Biochemical and anthropometric determinants of serum B and pre-B-lipoproteins in children The Bogalusa heart study. Arteriosclerosis 1982;2:325-34.

13 Haines AP, Imeson JD, Meade TW. Skinfold thickness and cardiovascular risk factors. Am $\mathcal{F}$ Epidemiol 1987;126:8694.

14 Freedman DS, Srinivasan SR, Burke GL, et al. Relation of body fat distribution to hyperinsulinaemia in children and adolescents: the Bogalusa heart study. Am $\mathcal{F}$ Clin Nutr 1987;46:403-10.

15 Shear CL, Freedman DS, Burke GL, Harsha DW, Berenson GS. Body fat patterning and blood pressure in children and young adults. The Bogalusa heart study. Hypertension 1987;9:236-44.

16 Freedman DS, Srinivasan SR, Harsha DW, Webber LS, Berenson GS. Relation of body fat patterning to lipid and lipoprotein concentrations in children and adolescents: the Bogalusa heart study. Am f Clin Nutr 1989;50:930-9.

17 Valdez R, Athens MA, Thompson GH, Bradshaw BS, Stern MP. Birthweight and adult health outcomes in a biethnic population in the USA. Diabetologia 1994;37:624-31.

18 Davis JA. Findings could be influenced by stage of puberty. BMF 1994;308:1634 [letter] 